\title{
Seasonal-dependent effect of temperature on the response of adenylate cyclase to FSH stimulation in the oviparous lizard, Podarcis sicula
}

\author{
L Borrelli, R De Stasio, C M Motta, E Parisi ${ }^{1}$ and S Filosa \\ Department of Evolutionary and Comparative Biology, University of Naples Federico II, Via Mezzocannone 8, 80134 Naples, Italy \\ ${ }^{1}$ CNR Institute of Protein Biochemistry and Enzymology, Viale Marconi 10, 80125 Naples, Italy \\ (Requests for offprints should be addressed to S Filosa, Department of Evolutionary and Comparative Biology, University of Naples Federico II, \\ Via Mezzocannone 8,80134 Naples, Italy; Email: filosa@dgbm.unina.it)
}

\begin{abstract}
The study of environmental factors affecting vertebrate reproduction has long interested both developmental and evolutionary biologists. Although photoperiod has been considered to be an important environmental parameter for vertebrates such as birds, temperature is probably a primary external factor responsible for reproductive cyclicity in reptiles. In spite of the progress made in the understanding of reptilian reproductive strategies and adaptations, much remains to be learned about the interplay between endocrine physiological factors, such as hormones, and environmental parameters.

In this report, we have examined the effects of in vivo administered FSH on oocyte recruitment during the most significant periods of the reproductive cycle of the lizard, Podarcis sicula. The results show that when FSH is administered in proximity to the reproductive period, it stimulates oocyte growth and ovulation; when the hormone is
\end{abstract}

administered at the beginning of the winter stasis it affects ovarian activity without inducing ovulation. Ovarian adenylate cyclase activity is moderately sensitive to in vitro FSH stimulation during the pre- and post-reproductive periods. The sensitivity to hormone stimulation increases significantly during the reproductive period and winter stasis.

We have also tested the hypothesis that environmental temperature affects the responsiveness of ovarian adenylate cyclase to FSH stimulation. For such a purpose, we exposed animals to $28{ }^{\circ} \mathrm{C}$ or $4{ }^{\circ} \mathrm{C}$ in different periods of the ovarian cycle. The results show that, whenever the temperature applied mimics the thermal regime of the coming season, adenylate cyclase sensitivity to FSH shifts towards levels that anticipate the natural responsiveness. Journal of Endocrinology (2000) 167, 275-280

\section{Introduction}

To gain reproductive success, organisms have adopted a bewildering array of adaptive mechanisms. Among them, seasonal reproduction is an important strategy that, by restricting breeding to periods characterised by favourable climatic conditions, ensures a high rate of offspring survival (Crews 1979). A fundamental role in this strategy is played by environmental parameters, such as photoperiod and temperature, that may act as ultimate factors capable of modulating reproductive functions (Randall et al. 1998). Local environmental parameters have particular effects on the reproduction of poikilotherm vertebrates, and especially on the species living at high latitudes or altitudes that are exposed to dramatic changes in temperature and photoperiod. In lower vertebrates, photoperiod may control rhythmic activities by acting as a 'zeitgeber' of melatonin synthesis in the pineal gland (Randall et al. 1998). Temperature, on the other hand, has been postu- lated to be the main non-photic factor capable of driving a number of seasonal events, including reproduction (Firth et al. 1989).

Although the correlation between endogenous control mechanisms and environmental parameters has been investigated to some extent (Bronson 1985, Hastings et al. 1985), little information is available on how gonadal activities are influenced by environmental factors. For this reason, we carried out a study using Podarcis sicula, the wall lizard living in the temperate lowlands of southern Europe, as the experimental model. In this species, reproduction occurs with a single ovulatory wave in spring-summer and is preceded by typical morpho-physiological modifications of the ovary. These include an increase in the number and size of follicles, and the onset of vitellogenesis. At the end of the ovulatory period, the ovary enters a fall-winter stasis that lasts until the next spring (Filosa 1973).

In mammals, ovarian activity is under the control of hypophyseal gonadotrophins (Pierce \& Parson 1981). In 
reptiles, studies on the effect of gonadotrophins are usually performed with heterologous hormone preparations, because no reptilian gonadotrophin is available at the present time. However, in a previous study on the ovary of $P$. sicula, we demonstrated the presence in the lizard genome of nucleotide sequences homologous to mammalian follicle-stimulating hormone (FSH) (Borrelli et al. 1997). As in other reptiles, heterologous FSH is capable of inducing oogonial proliferation, oocyte growth and differentiation, vitellogenesis (Limatola \& Filosa 1989), estrogen production (Callard et al. 1976, Lance \& Callard 1978) and ovulation (L Borrelli, R De Stasio, CM Motta, E Parisi \& S Filosa, unpublished observation). We have previously demonstrated that the hormone acts by stimulating adenylate cyclase activity present in the membranes of follicular cells (Borrelli et al. 1997).

The aim of this report is to clarify the effects of endogenous and exogenous factors on gonadal activity in Podarcis sicula, during the most significant periods of the reproductive cycle. For such a purpose, we have studied, first, the effect of FSH on both oocyte recruitment and ovarian adenylate cyclase activity, and secondly, the influence of temperature on the responsiveness of follicular adenylate cyclase to FSH. The results obtained show that the ovarian responsiveness to FSH and the oogonial recruitment are high at the onset of reproduction, decline soon afterwards, and are resumed in late fall. In animals exposed to a temperature close to that of the forthcoming season, the sensitivity of the ovarian adenylate cyclase to FSH stimulation varies in a way that always anticipates the natural responsiveness.

\section{Materials and Methods}

\section{Chemicals}

ATP (specific activity $1 \cdot 11 \mathrm{Tbq} / \mathrm{mmol}$ ) and $[2 \cdot 8$ $\left.{ }^{3} \mathrm{H}\right] \mathrm{cAMP}(1.2 \mathrm{Tbq} / \mathrm{mmol})$ were obtained from DupontNEN (Wilmington, DE, USA). Porcine FSH was from Sigma Chemicals (Poole, Dorset, UK). All other reagents were of the highest purity and were purchased from standard commercial sources.

\section{Animals}

Sexually mature female specimens of Podarcis sicula (6-8 cm, snout-vent length) collected by hand in the outskirts of Naples, were housed in groups of 6-15 animals in cages $(60 \times 40 \times 35 \mathrm{~cm})$ and were fed mealworms and water available ad libitum. Experiments were carried out for three consecutive years in March, June, September and December, i.e. in coincidence with the pre-reproductive, reproductive, and post-reproductive periods and with winter stasis (Filosa 1973). At sampling, the animals were anaesthetised with ether and killed by decapitation. Whole ovaries were processed for adenylate cyclase assay (see below) or fixed in ethanol:acetic acid $(3: 1 \mathrm{v} / \mathrm{v})$ and processed for wax embedding. Prefollicular (preleptoteneearly diplotene stages) and growing oocytes (diplotene stage surrounded by a follicular epithelium) were counted in serial sections.

\section{Treatment of animals with FSH}

Two doses of $125 \mu \mathrm{g} / \mathrm{animal}$ of porcine FSH (Sigma Chemicals), dissolved in saline, were administered i.p. every other day. The animals were killed five days after the beginning of the treatment. The hormonal dosage and time of treatment were chosen according to a previously published work (Limatola \& Filosa 1989).

\section{Exposure of animals to different temperatures}

In order to realise conditions of photoperiod typical of each season, groups of six animals were housed in artificially lit rooms; the lights were controlled by a timer. We used photoperiods of $13 \mathrm{~h}$ light: $11 \mathrm{~h}$ darkness in September, $8 \mathrm{~h}$ light:16 h darkness in December, $11 \mathrm{~h}$ light: $13 \mathrm{~h}$ darkness in March and $16 \mathrm{~h}$ light: $8 \mathrm{~h}$ darkness in June. The animals were exposed for seven days at $28{ }^{\circ} \mathrm{C}$ in a room equipped with a thermostat-regulated heater, and at $4{ }^{\circ} \mathrm{C}$ in a refrigerated room. These temperatures were chosen because they correspond to the maximum and minimum average temperature registered in the area of capture. The exposure time to the experimental temperatures was chosen after a number of trials demonstrating that maximal ovarian activity response could be obtained after 7 days.

\section{Adenylate cyclase assay}

Ovarian follicles, deprived of the external connectival theca under a dissection microscope, were homogenised in $5 \times 10^{-3}$ M Tris-HCl buffer, $\mathrm{pH} 7 \cdot 4$, containing $0 \cdot 25 \mathrm{M}$ sucrose, using a Dounce homogeniser. The homogenate was centrifuged at $12000 \mathrm{~g}$ for $15 \mathrm{~min}$ at $4{ }^{\circ} \mathrm{C}$ and the resulting pellet, containing the membrane fraction, was resuspended in the homogenisation buffer.

Adenylate cyclase activity was measured from the conversion of $\left[\alpha-{ }^{32} \mathrm{P}\right]$ ATP into cyclic AMP according to the method of Salomon et al. (1974). The reaction mixture contained: $0.03 \mathrm{M}$ Tris- $\mathrm{HCl}, \mathrm{pH} 7 \cdot 4 ; 7.5 \times 10^{-4} \mathrm{M}$ EDTA; $\quad 0.01 \mathrm{M}$ caffeine; $4 \times 10^{-3} \mathrm{M} \quad \mathrm{MgCl}_{2}$; $5 \times 10^{-4} \mathrm{M}$ dithiothreitol; $0 \cdot 02 \mathrm{M}$ creatine phosphate; $1 \times 10^{-4} \mathrm{M}$ cAMP; 2 units creatine phosphokinase; $1 \times 10^{-4}$ M ATP; 92.5-45.0 KBq [ $\left.\alpha-{ }^{32} \mathrm{P}\right]$ ATP (Dupont NEN). The reaction was carried out at $30^{\circ} \mathrm{C}$ for $60 \mathrm{~min}$ with or without $10^{-6} \mathrm{M}$ porcine FSH. Radioactivity was measured by liquid scintillation counting. Each data point was determined in duplicate and expressed as the 


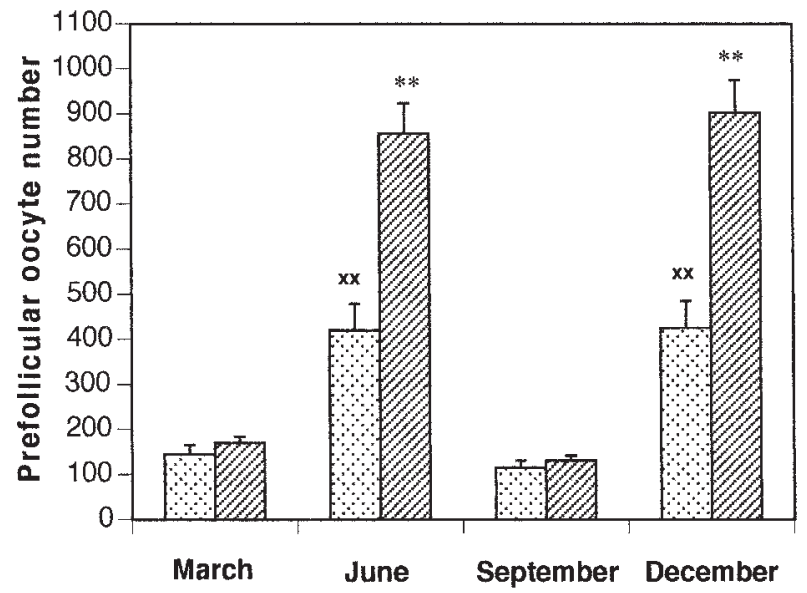

Figure 1 Changes in prefollicular oocyte number in control (crosshatched bars) and FSH-treated (hatched bars) animals in the four most significant months of the ovarian cycle. Values shown are means \pm S.D. of the oocyte number per animal. The value of $F$ determined by ANOVA was $40 \cdot 2$ ( $F$ at $P=0.01$ with 7 and 49 degrees of freedom was $3 \cdot 41$ ). The results of the Tukey test run at $P=0.01$ showed that control groups in June and December were significantly different $\left({ }^{\mathrm{xx}}\right)$ from the groups in March and September, and that the FSH-treated groups were significantly different $\left({ }^{* *}\right)$ from the relative controls.

mean \pm s.D. Protein content was analysed on membrane preparations according to Lowry et al. (1951).

\section{Statistics}

Statistical tests on experimental data sets were performed with programs contained in the Systat package, version 5.0 (SYSTAT Intelligent Software, Evanston, IL, USA).

\section{Results}

Effect of FSH on the ovary of P. sicula

In P. sicula, the number of prefollicular oocytes present in the ovary changes significantly throughout the year. The average number which is 144 in March, almost triples in June, in conjunction with the onset of the reproductive period, and decreases again to 110-120 in September. A new increase in the number of oocytes occurs in late fall: at this time, the ovary contains an average of 470 oocytes (Fig. 1).

As exogenous gonadotrophins have been shown to be fully bioactive in reptiles in which they are capable of inducing steroidogenesis (Callard et al. 1976, Lance \& Callard 1978), we administered mammalian FSH to a group of female lizards during the four most significant periods of the reproductive cycle. The results reported in Fig. 1 show that the oocyte number approximately doubles when the treatment is carried out in December and June,

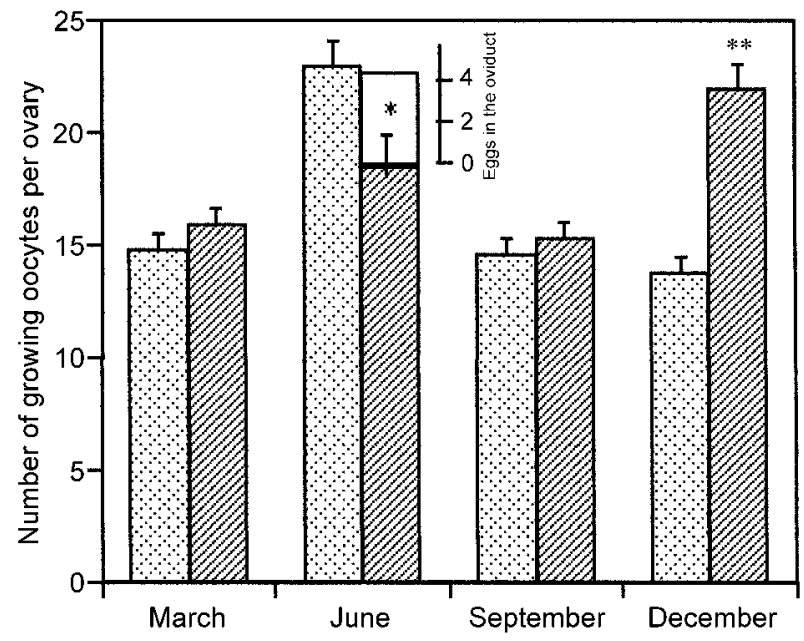

Figure 2 Number of growing oocytes in control (cross-hatched bars) and FSH-treated (hatched bars) animals in the four most significant months of the ovarian cycle. Values are shown as means \pm S.D. The value of $F$ determined with ANOVA was $17 \cdot 5$ ( $F$ at $P=0.01$ with 7 and 37 degrees of freedom was $3 \cdot 04$ ). Significance at $P=0.01\left(^{* *}\right)$ and $P 0.05\left(^{*}\right)$ between FSH-treated groups and the corresponding controls was determined by Tukey test. The stacked bar (open bar) represents the number of eggs found in the oviduct of FSH-treated animals in June.

but remains unchanged in animals treated in September and March. The increase in prefollicular oocyte number observed in December both in control and FSH-treated females suggests the existence of an ovarian recrudescence before winter.

FSH also affects the number of growing oocytes in the gonad. Between September and March, the average number of growing oocytes is 14 , and during the reproductive period (i.e. June) this number rises to 23. Following FSH treatment, significant changes in the oocyte number are observed in animals treated in December and June. In December, under the effect of FSH stimulation, the oocyte number rises to 22 , which corresponds to the number usually found during the reproductive period. In June, the oocyte number apparently decreases to about 18 , but at the same time an average of four mature eggs are found in the oviduct (Fig. 2). Hence, FSH administered during the reproductive period does not cause a further increase in the oocyte number, but it stimulates the differentiation of large oocytes into mature eggs.

\section{Sensitivity of ovarian adenylate cyclase activity to gonadotrophin throughout the ovarian cycle}

We have previously shown that FSH stimulates adenylate cyclase activity in follicular cell membranes and increases cAMP production in isolated ovaries in the lizard (Borrelli et al. 1997). For this reason, we decided to use FSH- 
stimulated adenylate cyclase as a suitable biochemical marker of the ovarian activity in Podarcis sicula. We have not used gonadotrophin-releasing hormone $(\mathrm{GnRH})$ to increase endogenous FSH artificially, because it has been reported that $\mathrm{GnRH}$, besides its known secretagogue activity, may act directly on the ovary (Sirotkin et al. 1994, Zanagnolo et al. 1996, Yano et al. 1997).

The results in Table 1 show that, under environmental temperature conditions, the sensitivity of the lizard ovarian adenylate cyclase to FSH changes throughout the year. The results of one tailed paired $t$-tests show that adenylate cyclase activity is significantly enhanced by the presence of FSH in the reaction mixtures. The enzyme activity is moderately but still significantly sensitive to hormone in March $(t=5 \cdot 3, n=6, P=0003)$ and in September $(t=8 \cdot 2$, $n=6, P<0001)$, with $30-40 \%$ stimulation over the basal level. The sensitivity of adenylate cyclase to gonadotrophin increases in line with the reproductive season and during the winter stasis: FSH stimulation reaches a level of about $100 \%$ in June $(t=8 \cdot 4, n=7, P<0001)$ and in December $(t=10 \cdot 7, n=6, P<0001)$.

Effect of temperature on adenylate cyclase sensitivity to FSH stimulation

The effects of temperature treatments were tested by comparing the responsiveness of ovarian adenylate cyclase to FSH stimulation in groups of animals maintained at the experimental temperatures of $28^{\circ} \mathrm{C}$ or $4{ }^{\circ} \mathrm{C}$ and at the seasonal temperatures. The results of these experiments, reported in Table 1, were subjected to an ANOVA statistical test with a covariance model, using temperature and period of the year as independent variables, the FSH-stimulated activity as dependent variable and the basal activity as covariate. Before analysing the data, homogeneity of slopes was tested with respect to categorial variables: the results proved the absence of significant interactions between covariate and temperature $(\mathrm{F}=2 \cdot 2$, $P=0 \cdot 095)$, and covariate and period $(\mathrm{F}=2 \cdot 4, P=0 \cdot 096)$. The analysis of the covariance model showed that the effect of the interaction of period and temperature on FSH-stimulated activity was significant $(\mathrm{F}=3 \cdot 1, P=0 \cdot 01)$. This prompted us to perform an ANOVA with Tukey post-hoc tests. In order to minimise the effects that might invalidate ANOVA, in this test we used the logarithmic transformation of the whole data set. The diagrams in Fig. 3 show the effect produced by FSH on ovarian adenylate cyclase of animals belonging to three different experimental groups kept at the environmental temperature, at $28^{\circ} \mathrm{C}$ and at $4{ }^{\circ} \mathrm{C}$. In March, the sensitivity of adenylate cyclase to $\mathrm{FSH}$ stimulation in animals kept at $28^{\circ} \mathrm{C}$ is significantly higher $(\mathrm{F}=5 \cdot 8, n=6, P=0 \cdot 013)$ than the other two groups. In June, the sensitivity to hormone stimulation decreases in animals at $28{ }^{\circ} \mathrm{C}(\mathrm{F}=17, n=7$, $P<0 \cdot 01$ ), whereas the responsiveness to $\mathrm{FSH}$ is not significantly affected by a temperature of $28^{\circ} \mathrm{C}$ applied in

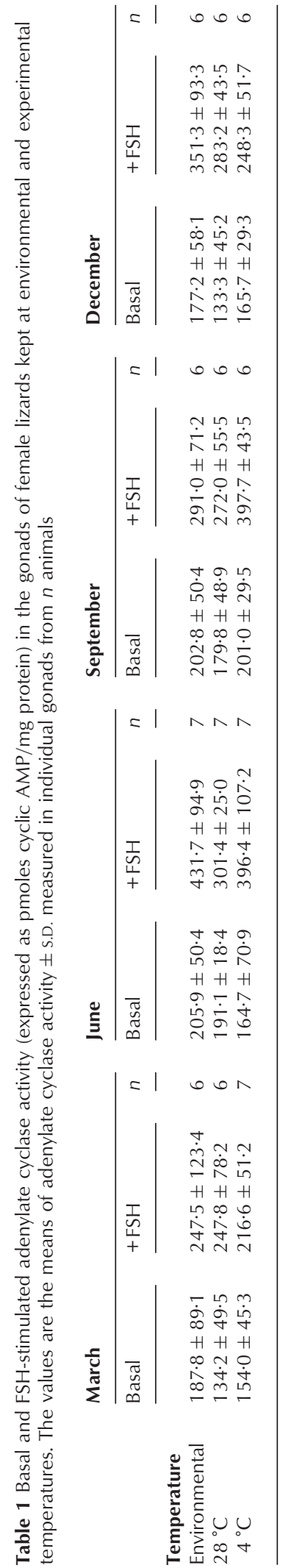

Journal of Endocrinology (2000) 167, 275-280 www.endocrinology.org 

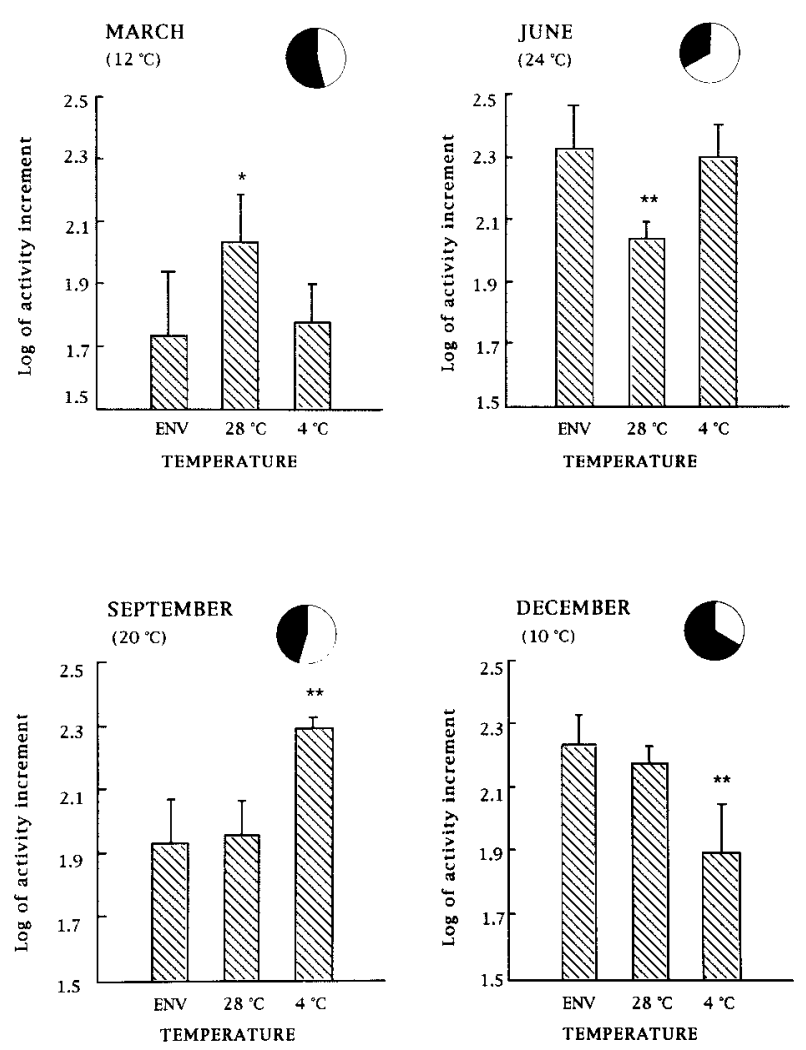

Figure $3 \mathrm{FSH}$-induced increments in ovarian adenylate cyclase activity in animals kept at experimental $\left(28^{\circ} \mathrm{C}\right.$ and $\left.4{ }^{\circ} \mathrm{C}\right)$ and environmental (Env) temperatures during the most significant months of the reproductive cycle. The activity increments produced by FSH, logged to the base 10, were calculated from the data reported in Table 1. Significance was assessed by ANOVA using Tukey one tailed test (** significant at $1 \%$ level; * significant at $5 \%$ level). The average seasonal temperatures and the natural photoperiods (pies) are shown at the top of each diagram.

September and December. The response to the low temperature $\left(4^{\circ} \mathrm{C}\right)$ shows an entirely different pattern: the temperature treatment results in no significant effect on the enzyme sensitivity to hormone stimulation in March and June, whereas in September the enzyme stimulation is significantly higher $(\mathrm{F}=22 \cdot 7, n=6, P<0 \cdot 01)$ in animals kept at $4{ }^{\circ} \mathrm{C}$. Finally, in December, the enzyme sensitivity to $\mathrm{FSH}$ decreases in the group at $4{ }^{\circ} \mathrm{C}(\mathrm{F}=16 \cdot 4, n=6$, $P<0 \cdot 01)$. It is noteworthy that a temperature of $28^{\circ} \mathrm{C}$ in March and in June shifts the sensitivity of adenylate cyclase to FSH towards values typical of June and September respectively, while exposure to a temperature of $4{ }^{\circ} \mathrm{C}$ in September and December induces a condition typical of December and March respectively.

\section{Discussion}

In the present report, we describe the effect of FSH on the ovarian activity in Podarcis sicula and the influence of temperature on the responsiveness of adenylate cyclase to FSH stimulation. Our results demonstrate that the effect of the in vivo FSH treatment on the ovary is particularly evident in two periods of the ovarian cycle, i.e. in early summer, at the onset of the breeding period, and in early winter, when the ovary undergoes a resumption of oogonial recruitment in spite of the unfavourable environmental conditions. When the hormone is administered in June it brings about an increase in the number of prefollicular oocytes, and stimulates oocyte growth as well as egg deposition. In December, FSH treatment causes effects similar to those observed in June, but fails to induce egg deposition. The reproductive cycle is also characterised by changes in the responsiveness of adenylate cyclase activity to FSH: the periods of maximal sensitivity to hormone stimulation, one in June and another in December, coincide with the two peaks of ovarian activity. All these observations together suggest that, in the females of this species, a partial recrudescence of ovarian activity occurs in early winter. This phenomenon, described also for the male gonad (Angelini et al. 1986), can be explained by assuming that $P$. sicula originally had two seasonal ovulatory waves, one in the summer and another in the fall, similar to the lizards normally living in warm habitats (Angelini \& Ghiara 1984). According to Arnold (1989), P. sicula was originally a warm-adapted species living in North Africa or the Middle East, and only later did it migrate to southern Europe. Our hypothesis is that when this species moved to a thermal regime with cold winters, it adapted to the new environmental conditions by suppressing the ovulatory wave in the fall, in order to leave a single reproductive episode in spring, a time suitable for maximal offspring survival.

The contrast between the bimodal pattern of ovarian activity and the pattern of the seasonal temperatures, which in southern Europe show a single peak in spring-summer, indicates that a complex interaction exists between endogenous control mechanisms and environmental temperature. For such a reason, we have studied the effect of temperature on the sensitivity of adenylate cyclase to FSH stimulation because the change in the activity of this enzyme seems to be correlated with the morphological modifications observed in the ovary during the reproductive cycle. In addition, the receptortransducer-effector system constituting adenylate cyclase is a simpler model compared with the complexity of the whole ovary. Our data show that the sensitivity of ovarian adenylate cyclase to FSH may be cued by temperature according to a well-defined programme. If the applied temperature follows the trend of the natural thermal regime, the sensitivity of adenylate cyclase to FSH approaches the level typical of the coming season. Indeed, exposure to $28^{\circ} \mathrm{C}$ in March and in June results in a sensitivity level to FSH that is shifted towards the values observed in June and in September respectively; whereas exposure to $4{ }^{\circ} \mathrm{C}$ in September and December induces a 
condition typical, respectively, of December and March. The enzyme sensitivity does not vary if the temperatures applied do not agree with the trend of the natural thermal cycle, like $4{ }^{\circ} \mathrm{C}$ in March or June and $28^{\circ} \mathrm{C}$ in September or December.

Our results suggest that temperature plays a very relevant role in the reproduction of $P$. sicula. However, this does not rule out the possibility that in P. sicula, as in other ectotherms, the annual reproductive cycle is regulated by the interplay between environmental temperature and photoperiod (Vivien-Roels 1985). It has been shown that the interaction of thermal and photoperiodic factors modulates the daily rhythm of melatonin production in reptilians (Firth \& Kennaway 1989, Firth et al. 1989). In such a context, an interesting observation is that in frog retina, serotonin $\mathrm{N}$-acetyl transferase activity, the key enzyme involved in the regulation of melatonin synthesis, is sensitive to differences in the environmental temperature (Valenciano et al. 1994). In this species, a nerve fibre connection has been demonstrated between the frontal organ, i.e. the intracranial component of the pineal complex, and skin (Guglielmotti et al. 1995).

In conclusion, the evidence presented here shows that gonadal processes are synchronised with the temperature variations through a mechanism that regulates ovarian activities, such as adenylate cyclase sensitivity to gonadotrophin stimulation. The anticipation of the natural thermal regime elicits a physiological response in the ovary that is typical of the coming season. The present data also support the hypothesis that remains of a second reproductive wave are still present in $P$. sicula. The suppression of this winter reproductive wave may be regarded as an adaptive strategy for offspring survival.

\section{Acknowledgements}

This study was supported by grants from 'MURSTProgetto Nazionale-Biologia ed Evoluzione del Meccanismi di Riconoscimento ed Interazioni Cellulari in Eurcaroti. L Borrelli was supported by a European Social Fund.

\section{References}

Angelini F \& Ghiara G 1984 Reproductive modes and strategies in vertebrate evolution. Bollettino Zoologico 51 121-203.

Angelini F, Ciarcia G \& Botte V 1986 Ambient cues and sexual cycle in the lizard P. sicula. In Endocrine Regulation as Adaptative Mechanisms to the Environment, pp 227-232. Eds I. Assenmacher \& J Boissins. Bordeaux: Biscaye Imprimeur.

Arnold EN 1989 Towards a phylogeny and biogeography of the Lacertidae: relationship within an Old-World family of lizards derived from morphology. Bulletin of the British Museum (Natural History of Zoology) 55 209-257.

Borrelli L, De Stasio R, Bovenzi V, Parisi E \& Filosa S 1997 Responsiveness of adenylate cyclase to pituitary gonadotropins and evidence of a hormone-induced desensitisation in the lizard ovary. General and Comparative Endocrinology 107 23-31.
Bronson FH 1985 Mammalian reproduction: an ecological perspective. Biology of Reproduction 32 1-26.

Callard IP, Callard GV, Lance V \& Eccles S 1976 Seasonal changes in testicular structure and function and the effects of gonadotropins in the fresh water turtle Chrysemys picta. General and Comparative Endocrinology 30 347-356.

Crews D 1979 Endocrine control of reproductive behaviour. In Endocrine Control of Sexual Behaviour, pp 167-222. Ed C Beyer. New York: Raven Press.

Filosa S 1973 Biological and cytological aspect of the ovarian cycle in Lacerta sicula sicula Rafinesque. Monitore Zoologico Italiano 7 151-165.

Firth BT \& Kennaway DJ 1989 Thermoperiod and photoperiod interact to affect the phase of the plasma melatonin rhythm in the lizard, Tiliqua rugosa. Neuroscience Letters 106 125-130.

Firth BT, Thompson MB, Kennaway DJ \& Belan I 1989 Thermal sensitivity of reptilian melatonin rhythms: 'cold' tuatara vs. 'warm' skink. American Journal of Physiology 256 R1160-R1163.

Guglielmotti V, Fiorino L \& Sada E 1995 A new cutaneous nerve fiber connection with the frontal nerve in the frog Rana esculenta: a morphological study. Brain Research Bulletin 37 337-342.

Hastings MH, Hebert J, Martensz ND \& Roberts AC 1985 Annual reproductive rhythms in mammals: mechanism of light synchronisation. Annals of the New York Academy of Sciences 453 182-204.

Lance V \& Callard IP 1978 in vivo responses of female snakes (Natrix fasciata) and female turtles (Chrysemys picta) to ovine gonadotropins (FSH and LH) as measured by plasma progesterone, testosterone, and estradiol levels. General and Comparative Endocrinology 35 295-301.

Limatola E \& Filosa S 1989 Exogenous vitellogenesis and micropinocytosis in the lizard Podarcis sicula, treated with follicle-stimulating hormone. General and Comparative Endocrinology 75 165-176.

Lowry OH, Rosebrough NJ, Farr AL \& Randall RJ 1951 Protein measurement with the Folin phenol reagent. Journal of Biological Chemistry 193 265-275.

Pierce J \& Parson TF 1981 Glycoprotein hormones: structure and function. Annual Review of Biochemistry 50 465-495.

Randall CF, Bromage NR, Duston J \& Symes J 1998 Photoperiodinduced phase-shifts of the endogenous clock controlling reproduction in the rainbow trout: a circannual phase-response curve. Journal of Reproduction and Fertility 112 399-405.

Salomon Y, Londons C \& Rodbell M 1974 A highly sensitive adenylate cyclase assay. Analytical Biochemistry 58 541-548.

Sirotkin AV, Nitray J, Kolena J \& Bulla J 1994 Cooperation between LH-RH and LH in direct action on the ovary: LH-RH stimulation of LH/hCG receptors, basal and LH-induced cAMP and cGMP release by porcine granulosa cells in vitro. Cell Signal 6 135-140.

Valenciano AI, Alonso-Gomez AL, De Pedro N, Alonso-Bedate M \& Delgado MJ 1994 Serotonin N-acetyltransferase activity as a target for temperature in the regulation of melatonin production by frog retina. European Journal of Physiology 429 153-159.

Vivien-Roels B 1985 Interactions between photoperiod, temperature, pineal and seasonal reproduction in non-mammalian vertebrates. In The Pineal Gland: Current State of Pineal Research, pp 187-209. Eds B Mess, C Ruzsas, L Tima \& P Pevet. Amsterdam: Elsevier.

Yano T, Yano N, Matsumi H, Morita Y, Tsutsumi O, Schally AV \& Taketani Y 1997 Effect of luteinizing hormone-releasing hormone analogues on the rat ovarian follicle development. Hormone Research 48 35-41.

Zanagnolo V, Dharmarajan AM, Hesla J \& Wallach EE 1996 Effect of a gonadotropin-releasing hormone analogue on rabbit ovarian function. Endocrinology 137 5400-5406.

Received 30 September 1999

Revised manuscript received 28 January 2000

Accepted 26 July 2000 